\title{
EXPERIMENTAL STUDY ON EVOLUTION OF RESIDUAL STRESS IN WELDED BOX-SECTIONS AFTER HIGH TEMPERATURE EXPOSURE
}

\author{
Weiyong Wang, ${ }^{1, *}$, Shiqi Qin², Venkatesh Kodur $^{3}$ and Yuhang Wang ${ }^{4}$ \\ 1. Professor, School of Civil Engineering, Chongqing University, Key Laboratory of New Technology for \\ Construction of Cities in Mountain Area (Ministry of Education), Chongqing, China \\ *(Corresponding author: E-mail: wywang@cqu.edu.cn) \\ 2. Graduate student, School of Civil Engineering, Chongqing University, Chongqing, China \\ 3. Professor, Department of Civil and Environmental Engineering, \\ Michigan State University, East Lansing, MI, 48824, USA. \\ 4. Professor, School of Civil Engineering, Chongqing University, Chongqing, China
}

Received: 20 August 2016; Revised: 18 May 2017; Accepted: 4 June 2017

\begin{abstract}
Presence of residual stresses can significantly influence the stiffness and fatigue life of steel structures. The extent of residual stress that develops in welded box-shaped sections at room temperature is extensively studied. However, there is limited data on the development of residual stresses after fire exposure. Such fire exposure has great influence on the residual stress distribution due to temperature induced plastic deformation and creep strains in steel. In order to provide benchmark data for the theoretical models and post-fire design recommendations, this paper presents results from an experimental investigation on the post-fire residual stresses in welded box-shaped sections. The tests are carried out by sectioning method, and two types of commonly used steels, mild Q235 steel with a nominal yield stress of $235 \mathrm{MPa}$ and high strength Q460 steel with a nominal yield stress of $460 \mathrm{MPa}$ are considered. The residual stresses were evaluated after exposing the specimens to $200^{\circ} \mathrm{C}, 400^{\circ} \mathrm{C}, 600^{\circ} \mathrm{C}$ and $800^{\circ} \mathrm{C}$ and cooling down to room temperature. Data from the tests clear show that the residual stresses decrease significantly with increase in specimen temperature. Further, results from the tests are utilized to propose simplified relations for temperature induced residual stresses in welded box-section of Q235 and Q460 steels.
\end{abstract}

Keywords: Residual stress, mild Q235 steel, high strength Q460 steel, high temperature, box-section

DOI: $10.18057 /$ IJASC.2018.14.1.5

\section{INTRODUCTION}

Steels used in construction applications are classified into different categories based on chemical composition, tensile strength properties, and fabrication process as carbon steels, low-alloy steels, heat-treated carbon steels, and high strength steels. Recent years have seen an increasing demand for high strength steels in construction applications due to superior properties of these steels, namely; high yield strength, good welding ability and corrosion resistance. Of these high strength steels, Q460 (with nominal yield strength of $460 \mathrm{MPa}$ ) steel welded box-sections, as well as mild Q235 (with nominal yield strength of 235MPa) steel welded box-sections, are widely used as compression elements in steel structures.

A structural steel member is most often not stress free initially, but is under built-in residual stresses induced during its manufacturing or welding process. Residual stresses in steel sections are stresses which exist due to uneven cooling or due to cold forming during fabrication process. These residual stresses are defined as internal stresses in an externally unloaded member and are therefore in internal equilibrium at cross-section, leading to instability condition in a structure. The presence of such residual stress can cause premature yielding and loss of stiffness. In practice, for critical welded steel member, post-weld heat treatment is often used and it is a stress relieving process whereby residual stresses are reduced by heating the whole structure to $550-650{ }^{\circ} \mathrm{C}$ for a preset 
time depending upon the plate thickness. The main aim of post-weld heat treatment is to relieve the residual stresses induced by the welding process.

For simulating the response of a structural member, proper residual stress distribution is to be incorporated in order to evaluate accurate response. The residual stress distribution in a welded box-section is characterized by tensile residual stresses $(+)$ at the weld ends and compression (-) at the middle of webs and flanges. The typical distributions of compressive and tensile residual stresses at ambient temperature are illustrated in Figure 1. The magnitude of the residual stresses in these welded box-shapes not only depends on the filler weld size and welding speed, but also depends on the steel type and thickness of steel plates.

In the last few decades, there have been numerous studies on the magnitude and distribution pattern of residual stresses in welded mild carbon steel sections [1]. Since the stress-strain curves and high-temperature properties [2] of high strength steel (HSS, yield strength $\geq 460 \mathrm{MPa}$ ) are different from that of mild carbon steel, it is hypothesized that the residual stresses in a HSS section to be different from that in a mild carbon steel section.

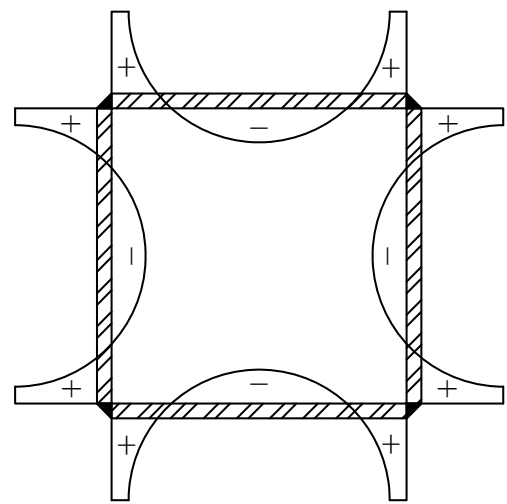

(a) Parabola curve distribution

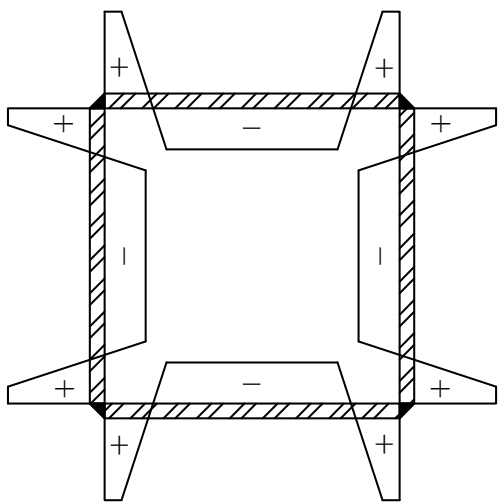

(b) Linear distribution

Figure 1. Typical Residual Stress Pattern in Welded Box Sections

In recent few years, the residual stress in welded high strength steel box section has called more attention to the researchers. In 2012, Wang and $\mathrm{Li}$ [3] measured the residual stresses of three welded flame-cut box-section columns with a nominal yield strength of $460 \mathrm{MPa}$ by both sectioning and hole-drilling methods. In 2013, Ban et al. [4] also tested the residual stresses of welded flame-cut box-section columns with a nominal yield strength of $460 \mathrm{MPa}$ by sectioning method. In 2015, Li et al. [5] measured the residual stress in welded high strength Q690 steel box sections, and proposed a distribution pattern. Ma et al. [6] investigated the residual stresses both in longitudinal and transverse directions on three hollow sections using wire-cutting method. In 2016, Khan et al. [7] investigated the induced residual stress distributions in square welded sections fabricated from $690 \mathrm{MPa}$ high strength steel plates with single and multiple weld passes.

All the above reported studies have focused on the residual stress of welded box-shaped sections at ambient conditions, and there is limited research on post-fire induced residual stresses besides the one conducted on H-shaped sections by authors as a preliminary study on post-fire residual stress [8]. Results from this preliminary study showed that the welded H-shaped sections after high temperature exposure exhibit different residual stress distribution due to temperature induced plastic and creep deformations in steel. Further the residual stresses also influence the load carrying capacity of steel members after fire exposure. In order to accurately evaluate the post fire residual capacity of steel members, the magnitude of residual stress in steel sections is to be known. For this 
purpose, a comprehensive study on the residual stress distribution in welded box-shaped sections after high temperature exposure was undertaken. As part of this study, a series of tests were carried out to measure post fire residual stress after exposure to various temperatures in welded box-shaped sections, made of Q235 steel and Q460 steel. Using this residual stress data, two residual stress distribution models are proposed for evaluating temperature induced residual stresses in mild Q235 steel and high strength Q460 steel box-sections.

\section{MATERIAL PROPERTIES}

Two steels commonly used in construction, mild Q235 steel and high strength Q460 steel, were selected for fabricating welded box-shaped section. In order to determine the mechanical properties of these steels at room temperature, tensile strength test were carried out by utilizing a typical tensile strength testing machine. Tension coupons were cut from the same parent plates, with nominal thicknesses of $8 \mathrm{~mm}$, from which the residual stress test specimens are fabricated. The cutting direction was perpendicular to the rolling direction according to GB/T 2975-1998 [9]. An extensometer was fixed at the mid-length of each tension coupon to obtain longitudinal strains for accurate determination of elastic modulus. The linear variable displacement transducer (LVDT) inside the universal testing machine also recorded the displacement between the two clamps after the extensometer was removed when the strain reached 5\%. The tension coupons were tested in accordance with GB/T 228-2002 procedure [10].

Table 1 shows test results for 8 tension coupons, where $f_{\mathrm{y}}$ is the yield stress, $f_{\mathrm{u}}$ is the ultimate tensile stress, $\Delta$ is the percentage of elongation after fracture and $E$ is the Young's modulus. The stress-strain curve is generated utilizing extensometer data and the LVDT data and is plotted in Figure 2. It can be seen that the Q460 steel, does not exhibit same level of ductility and strain hardening as that of mild carbon Q235 steel. These different properties are likely to result in the difference of residual stresses between welded mild steel sections and high strength steel sections. The reduction factors for elastic modulus after exposure to different temperatures were derived based on recommendations documented in Ref. [11]-[12].

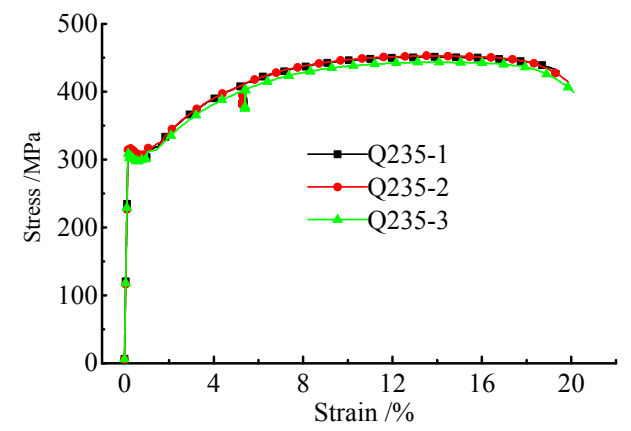

(a) Q235 steel

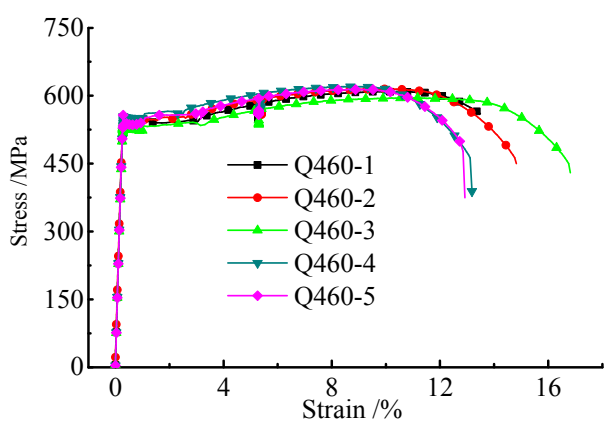

(b) Q460 steel

Figure 2. Stress-strain Curves of Q235 Steel and Q460 Steel 
Table 1. Mechanical Properties of Q235 Steel and Q460 Steel

\begin{tabular}{lllll}
\hline Coupon No. & $f_{\mathrm{y}} / \mathrm{MPa}$ & $f_{\mathrm{u}} / \mathrm{MPa}$ & $\Delta / \%$ & $E / \mathrm{GPa}$ \\
\hline Q235-1 & 300.5 & 451.5 & 19.5 & 204.125 \\
Q235-2 & 314.8 & 453.2 & 19.9 & 203.974 \\
Q235-3 & 303.6 & 444.0 & 20.1 & 203.829 \\
Mean value & 306.3 & 449.6 & 19.8 & 203.976 \\
Q460-1 & 539.3 & 609.5 & 13.5 & 208.792 \\
Q460-2 & 534.6 & 615.1 & 14.8 & 207.189 \\
Q460-3 & 527.2 & 595.8 & 16.8 & 206.509 \\
Q460-4 & 551.6 & 620.1 & 13.2 & 210.379 \\
Q460-5 & 537.7 & 614.9 & 12.9 & 209.843 \\
Mean value & 538.1 & 611.1 & 14.2 & 208.542 \\
\hline
\end{tabular}

\section{TEST PROGRAM}

A comprehensive test program was designed to undertake residual stress measurements after exposing welded box-shape section to high temperature conditions. The tests were carried out in two stages, namely, heating and cooling stage, on stub columns in an electric furnace, and then measurement of residual stress in specimens after post-temperature exposure condition, as well as at ambient temperature, by means of sectioning method.

\subsection{Method of Measurement}

Both destructive and non-destructive methods are adopted for determining residual stresses in structural members. X-ray, neutron or electron diffraction, ultrasonic methods and magnetic methods are grouped under non-destructive methods [13]. Sectioning method, grouped under destructive method, and commonly used for measuring residual stresses in structural steel members, was adopted to measure residual stresses in the current study.

\subsection{Test Specimens}

The residual stress distribution in stub columns fabricated with welded box-section is investigated in this study. The dimension of steel box sections used for tests are $\square 200 \mathrm{~mm} \times 200 \mathrm{~mm} \times 8 \mathrm{~mm} \times 8$ $\mathrm{mm}$, and the columns were fabricated with mild Q235 steel and high strength Q460 steel. The filled weld leg is of $8 \mathrm{~mm}$ thickness. For the welding, manual metal arc welding was used, and the shielding gasses were of $\mathrm{CO}_{2}$. The voltage of the welding gun was $25 \mathrm{~V}$, the amps were $230 \mathrm{~A}$ and the welding velocity was about $35 \mathrm{~cm} / \mathrm{min}$. The filler wire type for welding was JM-60, with yield strength of $545 \mathrm{MPa}$, and elongation after fracture at $25 \%$. The welding procedure as per Chinese standard JGJ81-2002 [15] was followed. The columns were of $1000 \mathrm{~mm}$ length and were cold-sawed into three segments in order to minimize end effects on residual stress results. Only the middle segment, with a length of $280 \mathrm{~mm}$, was used to measure the residual stress (as shown in Figure 3a). A total of 10 specimens were prepared for tests (shown in Figure 3b). Two specimens were tested at room temperature (labeled as $\square 235-20$ and $\square 460-20$ ) and the remaining eight specimens (labeled as $\square 235-200, \square 235-400, \square 235-600, \square 235-800, \square 460-200, \square 460-400, \square 460-600$ and $\square 460-800$ ) were tested after exposure to four target temperatures, namely $200^{\circ} \mathrm{C}, 400^{\circ} \mathrm{C}, 600^{\circ} \mathrm{C}$ and $800^{\circ} \mathrm{C}$. A unique label identification system is adopted for the specimens. For example, $\square 235-400$, where $\square$ denotes the section shape, the next three digits represent steel nominal yield strength in $\mathrm{N} / \mathrm{mm}^{2}$, and the following three digits refer to the target temperature. 


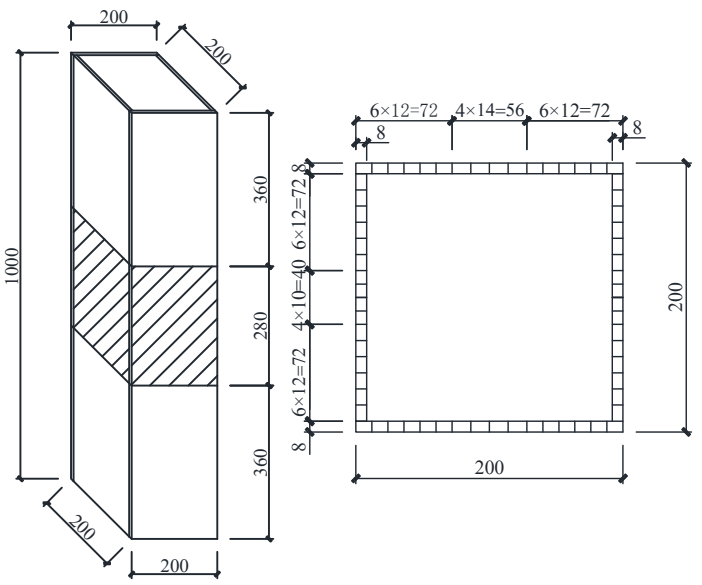

(a) Dimensions of specimen

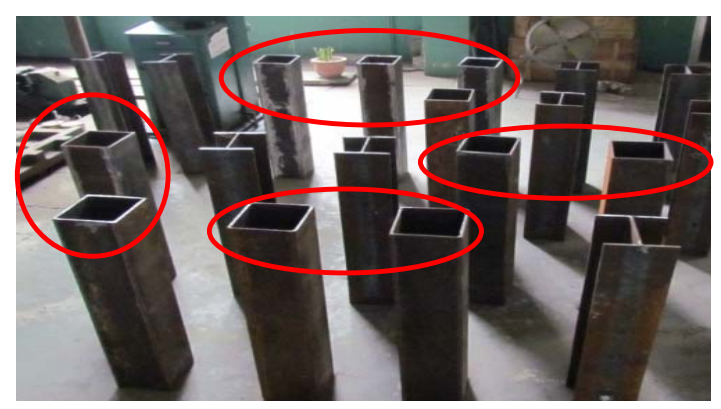

(b) View of specimens prior to testing

Figure 3. Dimension and Photo of Test Specimens

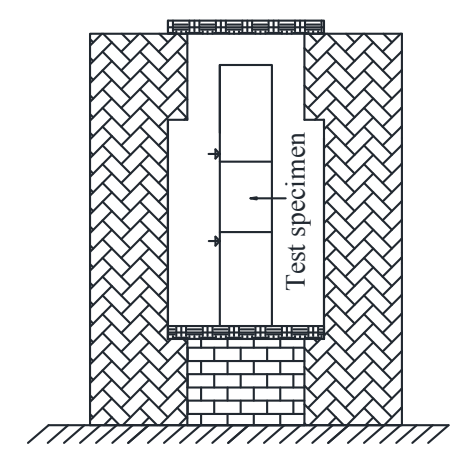

(a) Furnace and layout of specimen

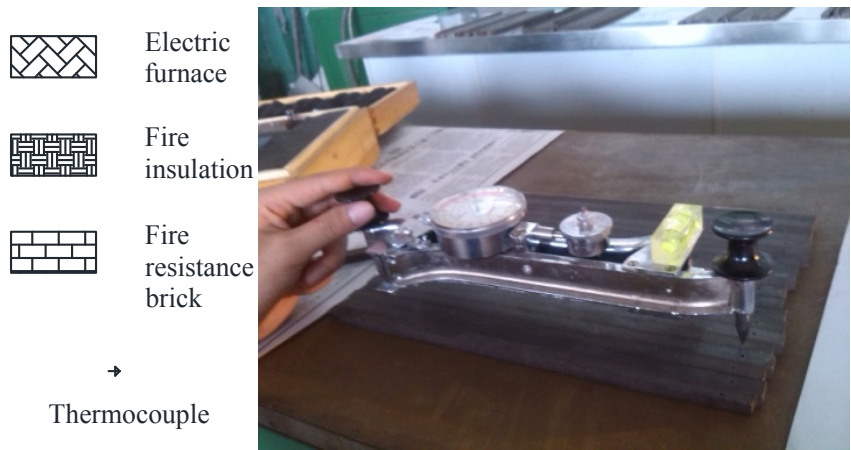

(b) Hand-held strain gauge for measuring strains

Figure 4. Test set-up for High Temperature Exposure and Measurement

\subsection{Test Set-Up}

The test set-up comprised of an electric furnace (as shown in Figure 4a), a wire-cutting machine and a hand-held strain gauge (as shown in Figure 4b). The electric furnace consists of a cylindrical chamber with a maximum heating length of $1500 \mathrm{~mm}$, and is capable of generating temperatures up to $1,100{ }^{\circ} \mathrm{C}$ at a pre-specified rate of temperature rise. Two built-in thermocouples are mounted inside the specimen to measure temperatures at upper and lower zone of middle segment of specimens and the average readings of these two thermocouples is taken as the specimen temperature.

\subsection{Test Procedure}

The following procedures were adopted for undertaking tests on specimens.

\section{(1) Fire exposure}

An electric furnace was utilized to heat the specimen to a specified target temperature as described above. In an actual fire incident, the time-temperature growth in a steel member, both during the heating and cooling stages of a fire, can be highly variable. In this study, however, only one time-temperature exposure was considered, in which the section is heated to a target temperature 
and then cools down naturally in air. The time-temperature curves, the specimens were subjected to during the heating phase and cooling phase is plotted in Figure 5.

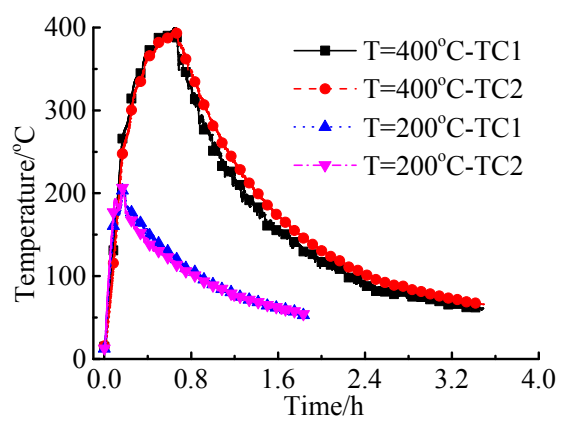

(a) Target temperature of $200-400^{\circ} \mathrm{C}$

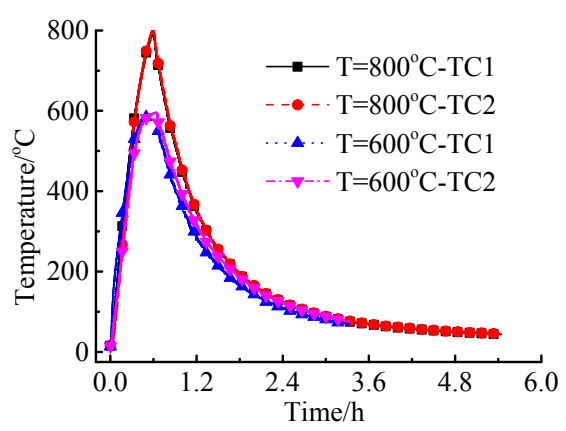

(b) Target temperature of $600-800^{\circ} \mathrm{C}$

Figure 5. Temperature-time Curve of Specimen during Fire Exposure

(2) Gauge holes drilling

Before drilling gauge holes, the specimens were cleaned to remove any rust deposited on the surface of steel by polishing the surface (shown in Figure 6a). After cleaning, cutting lines were drawn on the surface to mark the boundary of strips and a sign is marked on each strip. The dimension of each trip is shown in Figure 3a. In order to compensate any influence of temperature variation on the measured strain, a reference bar was fabricated to consider the strain induced by temperature variation. Finally, gauge holes were drilled on the sectioned segment with a strain gauge length of $250 \mathrm{~mm}$.

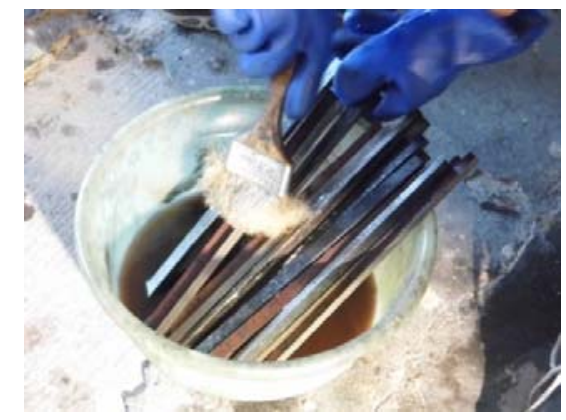

(a) Dust cleaning on strips

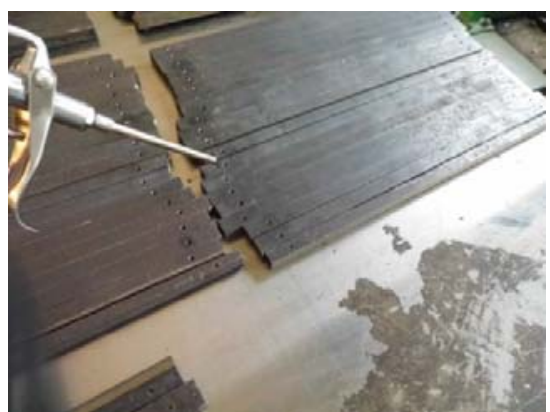

(b) Gauge hole cleaning

Figure 6. Photos of Specimen Strips Cleaning

\section{(3) Gauge length measurement}

Any dust accumulated on the gauge holes was cleaned (shown in Figure 6b), and then the length of standard strips, temperature compensating strips and the distance between gauge holes were measured. Average of three measurements was taken as the finial value. Utilizing the difference of standard trip and temperature compensating segment and sectioned strips, the length of temperature compensating segment and gauge holes was calculated. When the difference of three measurements exceeded $0.015 \mathrm{~mm}$, the measurements were abandoned and re-measurements were taken. Otherwise, the average value of three measurements was taken as the gauge length of temperature compensating segment $\left(L_{\mathrm{T} 1}\right)$ and sectioned trips $\left(L_{1}\right)$. 
(4) Cutting of strips

The column was cut into three segments along the lines on the surface of the column, and then the sectioning segment was cut into many strips. Finally, the coolant on the surface and gauge holes of strips was cleaned.

(5) Gauge length measurement after sectioning

Similar to the procedure used in step (2), the distance between two gauge holes on each strip and the length of temperature compensating segment was measured again to obtain the new length after the residual stresses release and temperature change. The average value of three measurements was taken to be the gauge length of temperature compensating segment $\left(L_{\mathrm{T} 2}\right)$ and sectioned trips $\left(L_{2}\right)$.

(6) Residual stress calculations

Based on the measured results in step (2) and (4), the strain of temperature compensating segment was obtained as $\varepsilon_{T}=\left(L_{T 2}-L_{T 1}\right) / L_{T 1}$; and the strain in strip was calculated as $\varepsilon=\left(L_{2}-L_{1}\right) / L_{1}$. The bending deformation in the strip was modified using the following equation:

$\bar{\varepsilon}=\varepsilon+(f / l)^{2} /\left(6(f / l)^{4}+1\right)$

where $f$ is deflection in strips at mid-span and $l$ is length of the strip.

The strain generated by residual stress release was obtained by subtracting temperature compensating strain from the total strain of strip, as $\varepsilon_{r}=\bar{\varepsilon}-\varepsilon_{T}$. According to Hooke's law, the residual stress on each trip was obtained as $\sigma_{\mathrm{r}}=\mathrm{E} \varepsilon_{r}$.

\section{TEST RESULTS AND COMPARISON}

Data generated from above tests was utilized to develop residual stress distribution of box-shaped steel sections made of Q235 steel and Q460 steel, after exposure to various temperatures.

\subsection{Test Results}

The difference in the length of each strip measured before and after sectioning was utilized to evaluate the residual stress as the product of released strain and elastic modulus and the resulting stresses is plotted in Figure 7, both for mild Q235 steel and for Q460 steel specimens. It can be seen from the figure that the residual stress in Q460 steel section is higher than that in Q235 steel at room temperature or after exposure to a given temperature. This can be mainly attributed to the fact that the mechanical properties of these two steels are different and higher the nominal yield strength of steel is, the higher the residual stress that develops. In addition, with increase in exposure temperature, the magnitude of residual stress decreases, irrespective of type of steel (Q235 or Q460). 


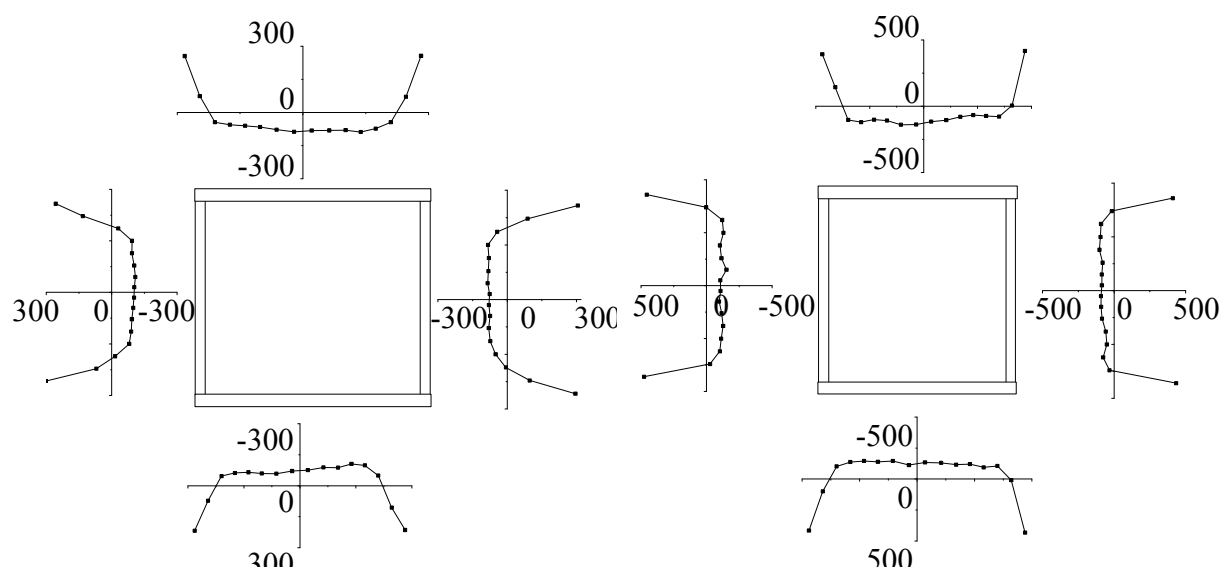

(a) At room temperature (Q235 steel)

(b) At room temperature (Q460 steel)
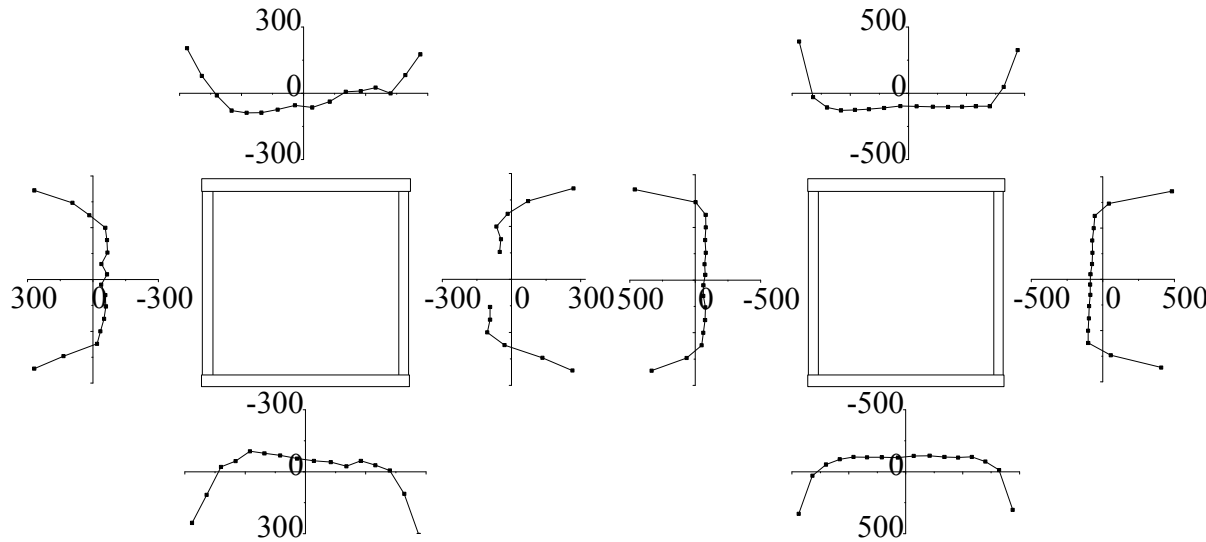

(c) After exposed to $200^{\circ} \mathrm{C}$ (Q235 steel)

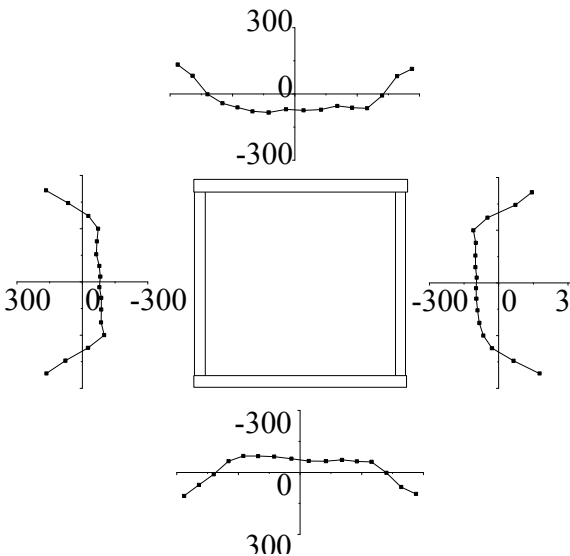

(d) After exposed to $200^{\circ} \mathrm{C}$ (Q460 steel)

(e) After exposed to $400^{\circ} \mathrm{C}(\mathrm{Q} 235$ steel)
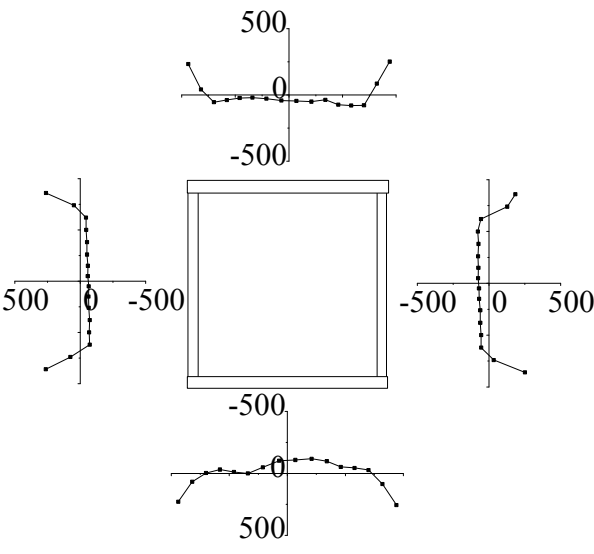

(f) After exposed to $400^{\circ} \mathrm{C}(\mathrm{Q} 460$ steel) 


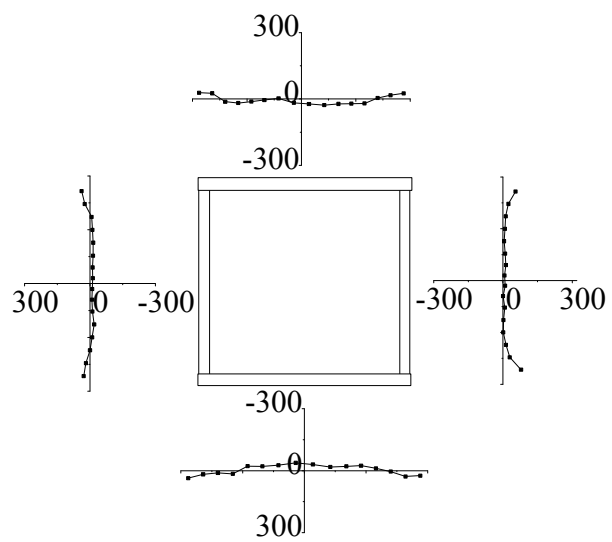

(g) After exposed to $600^{\circ} \mathrm{C}(\mathrm{Q} 235$ steel $)$

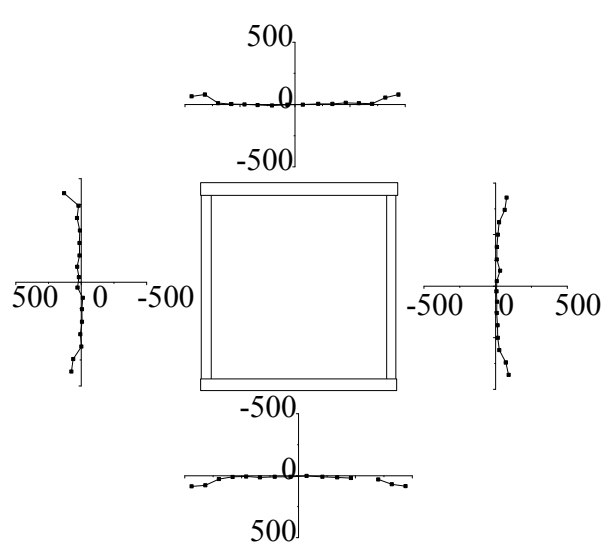

(h) After exposed to $600^{\circ} \mathrm{C}(\mathrm{Q} 460$ steel)

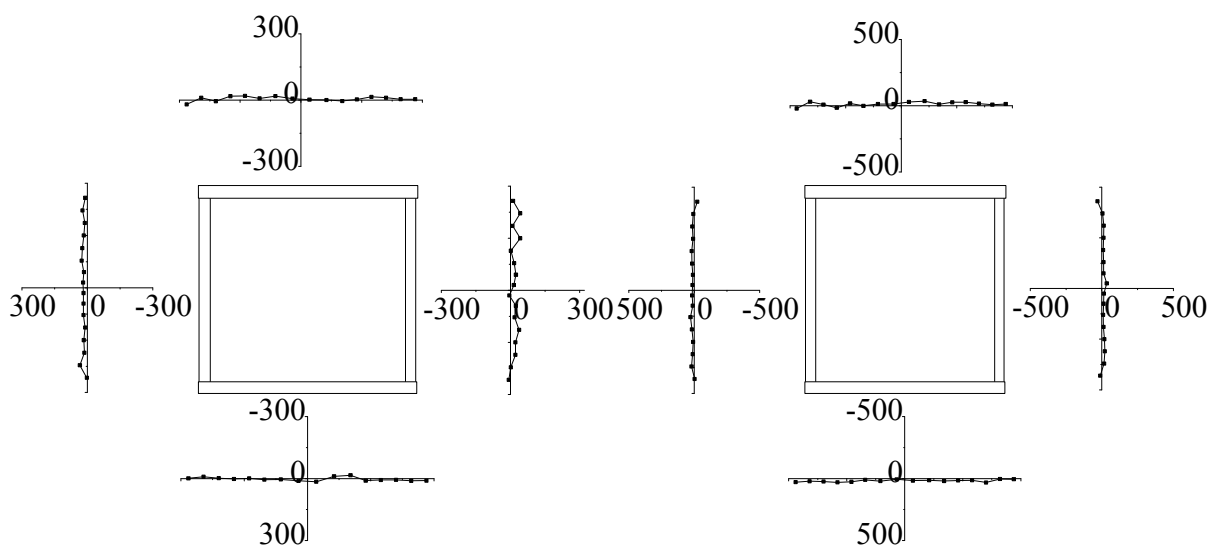

(i) After exposed to $800^{\circ} \mathrm{C}(\mathrm{Q} 235$ steel)

(j) After exposed to $800^{\circ} \mathrm{C}(\mathrm{Q} 460$ steel $)$

Figure 7. Residual Stress in Q235 and Q460 Steel Welded Box-shaped Sections after Exposure to Different Temperature

\subsection{Comparison of Residual Stress Ratio}

In order to compare variation of residual stresses in Q235 and Q460 steel specimens, the ratio of maximum residual stress to nominal yield strength at room temperature and after exposure to $400^{\circ} \mathrm{C}$ are plotted in Figure 8. This comparison clearly shows that, the ratio of maximum residual stress to nominal yield strength for Q235 steel is higher than that for Q460 steel. For example, the tensile residual stress ratio decreases from +1.10 to +0.94 for flanges and from +0.45 to +0.32 for webs at room temperature. It is well established that the residual stress to yield strength ratio, rather than the magnitude of residual stress, influence the global and local buckling behavior of steel members. Therefore, the member's ultimate capacity will benefit from the improvement in strength of steel. This conclusion was also reached in reported test results [3]. 


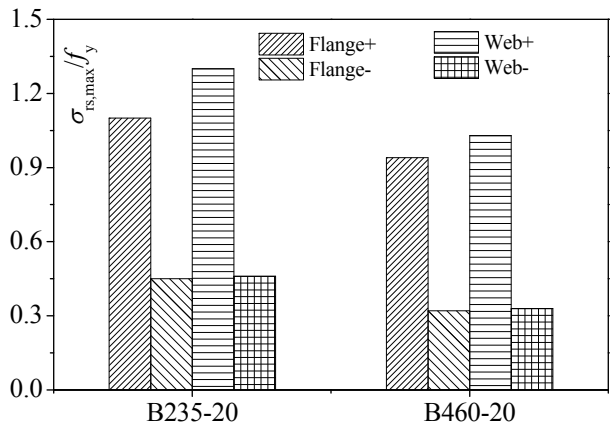

(a) At room temperature

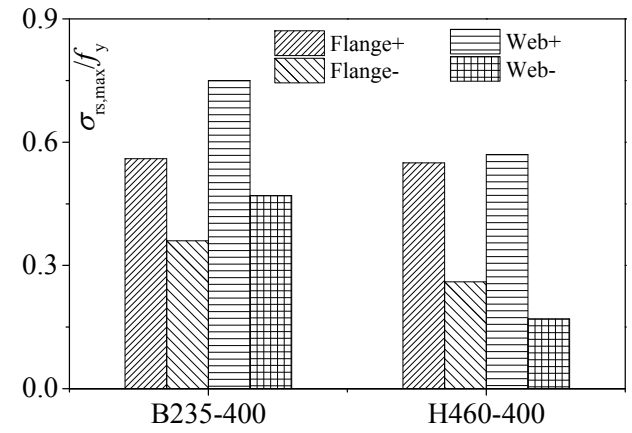

(b) After exposed to $400^{\circ} \mathrm{C}$

Figure 8. Comparison of Ratio of Maximum Residual Stress to Nominal Yield Strength

\subsection{Comparison of Reduction Factors}

In order to evaluate the effect of fire exposure on the magnitude of residual stress in welded steel sections, reduction factor of residual stresses, $\alpha_{1-\alpha_{4}}$, are plotted in Figure 9. This reduction factor is defined as the ratio of maximum residual stress (corresponding to tensile or compressive residual stress in flange and web, respectively) after fire exposure to that at room temperature. Data in Figure9 indicate that the reduction factor for residual stress decreases with increased exposure temperature. Moreover, the magnitude of reduction factor in flange and web, for both types of steel, decrease in a similar trend. Taking the temperature of $600^{\circ} \mathrm{C}$ as an example, the reduction factor is about 20\% for both Q235 steel and Q460 steel specimens.

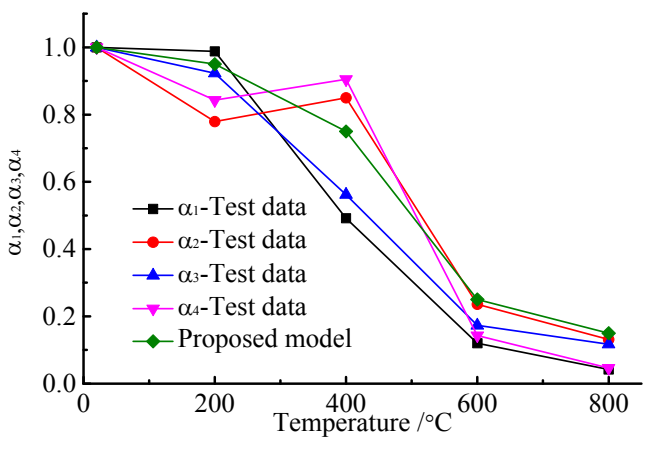

(a) Q235 steel

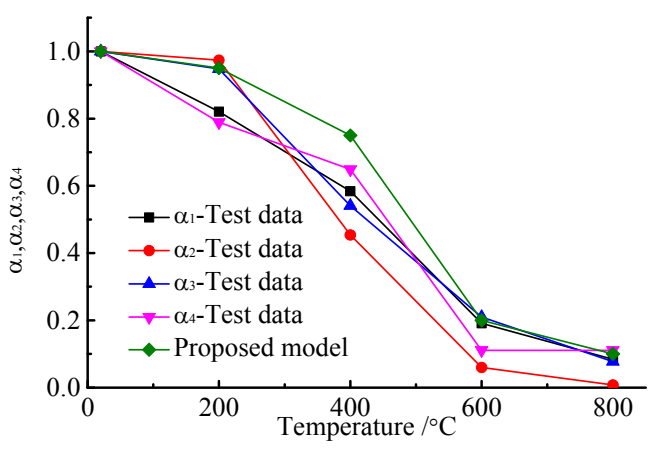

(b) Q460 steel

Figure 9. Reduction Factor of Residual Stress in Welded Box-section

\subsection{Comparison with Other Tests}

Since direct comparison with the residual stress pattern for the welded box-section after fire exposure was not available, welding residual stress after heat treatment was tested by Jiang et al. [16]. In the test, the specimens made of RQT701 steel with nominal yield stress of 690MPa were put into a furnace for heat treatment. The temperature history during thermal treatment process for test specimens is shown in Figure 10. As can be seen from the figure, the maximum temperature attained in test specimen is approximate $600^{\circ} \mathrm{C}$. Therefore, the residual stress of specimen after heat treatment is compared with the results of specimen after being exposed to $600^{\circ} \mathrm{C}$ and it is plotted in Figure11. The comparison indicates that the reduction factor of residual stress after heat treatment (RQT701 steel) is higher than that after fire exposure to $600^{\circ} \mathrm{C}(\mathrm{Q} 235$ and Q460 steel). The can be 
attributed to the fact that the welded steel plate used in the test by Jiang et al. [16] is $16 \mathrm{~mm}$ in thickness, which much thicker than the $8 \mathrm{~mm}$ thick plate used in this paper. In addition, the comparison also indicates that the high temperature exposure is as effective to reduce residual stress as heat treatment.

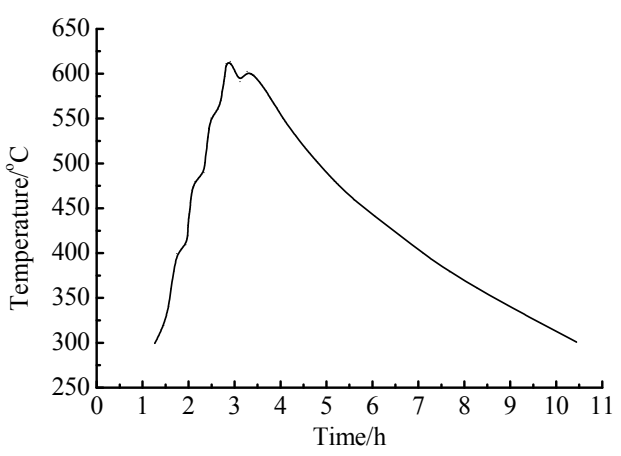

Figure10. Temperature History during Heat Treatment Process

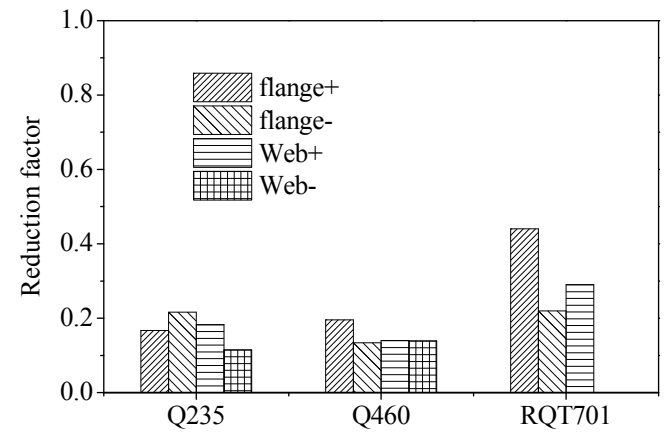

Figure 11. Comparison of Residual Stress after High Temperature Exposure and after Heat Treatment

The measured residual stresses in Q460 steel welded box-section at room temperature is also compared with the available residual stress reported in literature [4] for a similar section dimension, which is $\mathrm{B} 150 \times 150 \times 10 \times 13$. The comparison in Figure 12 shows that the distribution patterns are quite similar between different thicknesses of steel plate. However, the maximum magnitude of residual stress for section $\mathrm{B} 200 \times 200 \times 8 \times 8$ is higher than those for $\mathrm{B} 150 \times 150 \times 10 \times 13$. This may be attributed to the fact that the filled weld leg is similar $(8 \mathrm{~mm})$ even through plate thickness are different. For the thicker plate, the heat input during welding are relatively higher than that for thinner one. Consequently, it can be concluded that the thickness of plate and filled weld leg have significant effect on the maximum residual stress that develops.

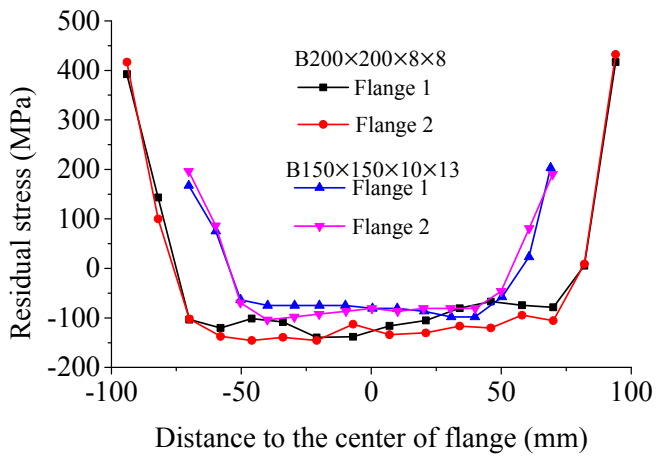

(a) Flange

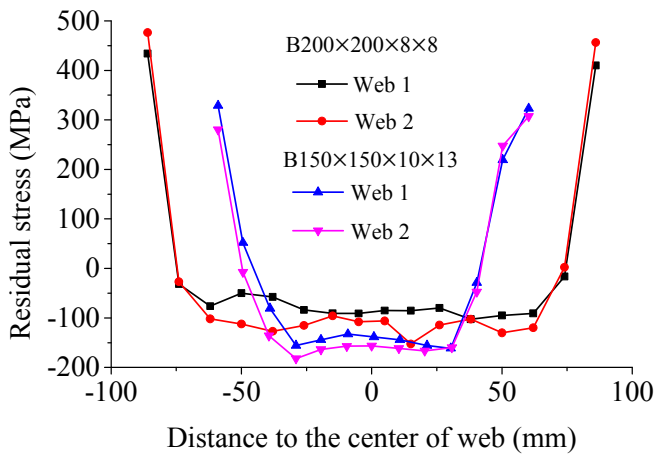

(b) Web

Figure 12. Comparison of Residual Stress in Welded Box Section with Different Plate Thickness 


\section{ROPOSED RESIDUAL STRESS RELATIONS}

The above comparison clearly indicates that grade of steel and exposure temperature play a critical role in determining residual stress distribution in welded steel sections. Thus these two factors are to be accounted for in evaluating residual stress distribution. A simplified relation is developed for accounting these two critical factors in evaluating residual stress. Due to complexity and significant effort involved in undertaking tests at various temperatures for each specimen type, only one cross section was considered in the test. As discussed in section 4.4, the thickness of plate also has some moderate influence on the magnitude of residual stress. Therefore, the residual stress model proposed here is applicable only to box-shaped sections of comparative thicknesses used in the test. In practice, steel plates of $6 \mathrm{~mm}$ to $10 \mathrm{~mm}$ thickness are used.

\subsection{Residual Stress Pattern}

For developing simplified relations for temperature induced residual stress of welded steel sections, equation proposed by Ban et al. [4] for room temperature residual stress formed the basis and are modified to account for temperature dependent influencing factors. The distribution pattern is symmetrical about the two axes due to the equilibrium of both axial force and bending moment within the section (as shown in Figure 13). The magnitude of stresses was labeled as follows: constant tensile stress in flanges $\sigma_{\mathrm{frt}}$, constant compressive stress in flange $\sigma$ frc, constant tensile stress in webs $\sigma_{\mathrm{wrt}}$ and constant compressive stress in web $\sigma_{\mathrm{wrc}}$. The multiple stepped functions of the distribution shape in flanges $\sigma_{\mathrm{fr}}(\mathrm{x})$ and webs $\sigma_{\mathrm{fr}}(\mathrm{y})$ are described in Eq. 2 and Eq. 3, respectively.

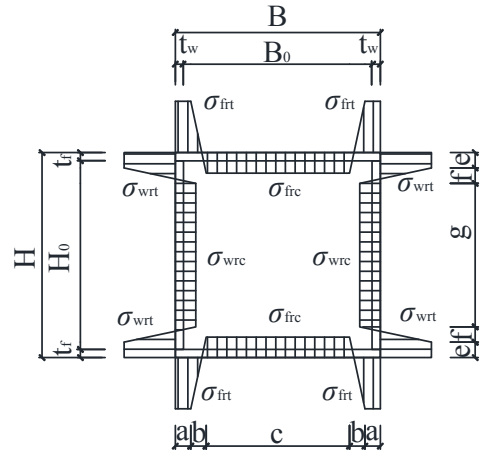

(a) Basic model

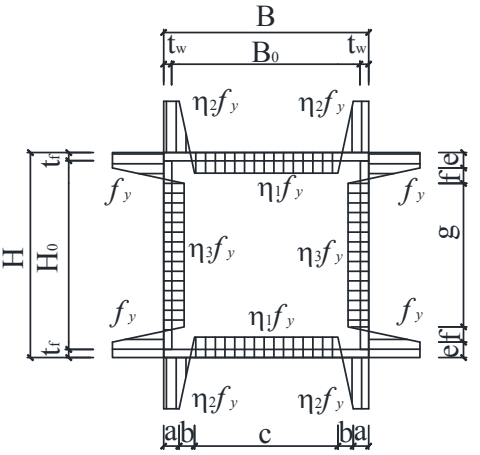

(b) At room temperature

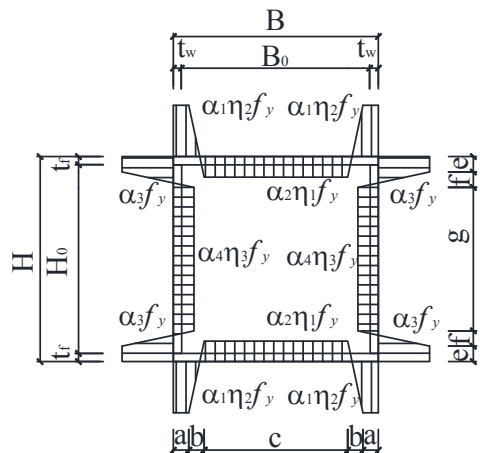

(c) After high temperature exposure

Figure 13. Proposed Distribution Mode of Residual Stress

$$
\begin{gathered}
\sigma_{\mathrm{fr}}(x)=\left\{\begin{array}{cc}
\sigma_{\mathrm{fit}}, & 0 \leq x \leq a \\
\sigma_{\mathrm{fit}}+\frac{\sigma_{\mathrm{frc}}-\sigma_{\mathrm{fit}}}{f}(x-a), & a \leq y \leq a+b \\
\sigma_{\mathrm{frc}}, & a+b \leq y \leq B / 2
\end{array}\right. \\
\sigma_{\mathrm{wr}}(y)=\left\{\begin{array}{cc}
\sigma_{\mathrm{wrt}}, & 0 \leq y \leq e \\
\sigma_{\mathrm{wrt}}+\frac{\sigma_{\mathrm{wrc}}-\sigma_{\mathrm{wrt}}}{f}(y-e), & e \leq y \leq e+f \\
\sigma_{\mathrm{wrc}}, & e+f \leq y \leq H / 2
\end{array}\right.
\end{gathered}
$$

where $a=t+B_{0} / 20 ; c=B-2 a-2 b ; d=t_{w}+6 h_{f} ; e=H_{0} / 20 ; g=h_{0}-2 e-2 f ; \quad \sigma_{f r c}=\eta_{1} f_{y}$; $\sigma_{f r t}=\eta_{2} f_{y} ; \sigma_{\mathrm{wrc}}=\eta_{3} f_{y} ; \sigma_{\mathrm{wrt}}=\eta_{4} f_{y} ;$ For Q235 steel: $\eta_{1}=\eta_{3}=0.375, \eta_{2}=1.0$; For Q460 steel: $\eta_{1}=0.25, \eta_{2}=0.9, \eta_{3}=0.20 ; b$ and $f$ can be determined according to equilibrium of residual stress across the entire section. 
To incorporate the fire exposure effects, the maximum magnitude of residuals stress at room temperature are modified to account for effect of fire exposure, through four coefficients $\alpha_{1}$ to $\alpha_{4}$. The results of test data reported in this paper were used to generate value of these coefficients for proposed models (as shown in Table 2). This way the proposed equation accounts for effects of steel type (Q235 and Q460) and temperature exposure $\left(20-800^{\circ} \mathrm{C}\right)$. Then the modified equation is extended to predict residual stress by establishing an equivalency between room temperature and after high temperature exposure.

Table 2. Comparison of Measured Stress Coefficient from Proposed Model with Test Data for Specimens

\begin{tabular}{cccccccccc}
\hline $\begin{array}{c}\text { Steel } \\
\text { type }\end{array}$ & $\begin{array}{c}\text { Exposure } \\
\text { temperature } /{ }^{\circ} \mathrm{C}\end{array}$ & \multicolumn{2}{c}{$\alpha_{1}$} & \multicolumn{2}{c}{$\alpha_{2}$} & \multicolumn{2}{c}{$\alpha_{3}$} & \multicolumn{2}{c}{$\alpha_{4}$} \\
\hline \multirow{2}{*}{ Test } & Model & Test & Model & Test & Model & Test & Model \\
steel & $200^{\circ} \mathrm{C}$ & 0.988 & 0.95 & 0.779 & 0.95 & 0.923 & 0.95 & 0.843 & 0.95 \\
& $400^{\circ} \mathrm{C}$ & 0.492 & 0.75 & 0.850 & 0.75 & 0.562 & 0.75 & 0.905 & 0.75 \\
& $600^{\circ} \mathrm{C}$ & 0.120 & 0.25 & 0.236 & 0.25 & 0.173 & 0.25 & 0.143 & 0.25 \\
& $800^{\circ} \mathrm{C}$ & 0.042 & 0.15 & 0.131 & 0.15 & 0.117 & 0.15 & 0.046 & 0.15 \\
$\mathrm{Q} 460$ & $200^{\circ} \mathrm{C}$ & 0.821 & 0.95 & 0.974 & 0.95 & 0.948 & 0.95 & 0.789 & 0.95 \\
steel & $400^{\circ} \mathrm{C}$ & 0.584 & 0.65 & 0.454 & 0.65 & 0.541 & 0.65 & 0.649 & 0.65 \\
& $600^{\circ} \mathrm{C}$ & 0.191 & 0.20 & 0.060 & 0.20 & 0.210 & 0.20 & 0.111 & 0.20 \\
& $800^{\circ} \mathrm{C}$ & 0.084 & 0.10 & 0.008 & 0.10 & 0.077 & 0.10 & 0.111 & 0.10 \\
\hline
\end{tabular}

\subsection{Validation of Proposed Relations}

In order to examine the validity of the above developed residual stress relation, the test data presented in this paper is selected for validation. Predicted residual stress in flange and web are compared against measured data on test specimens. Figure14 and Figure 15 present a comparison of predicted and measured residual stress for Q235 steel sections and Q460 steel sections, respectively. It can be clearly seen that there is a good agreement between the predicted and measured residual

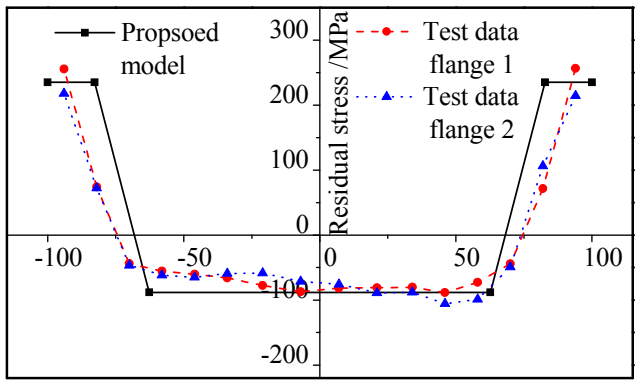

Distance from flange center $/ \mathrm{mm}$

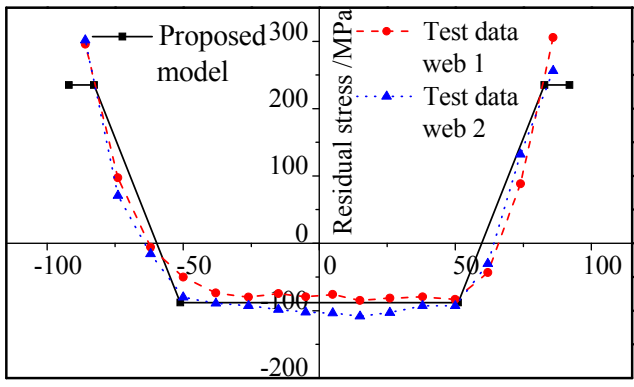

Distance from web center $/ \mathrm{mm}$

(a) At room temperature 


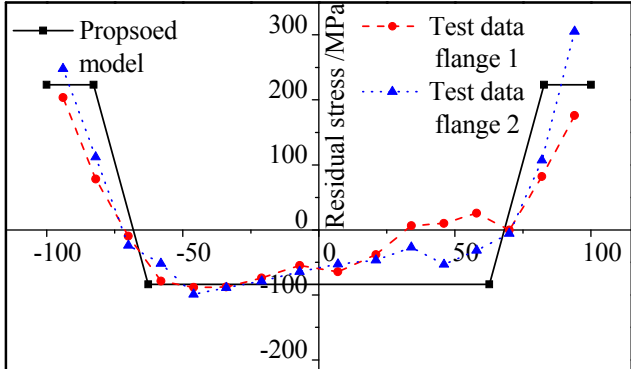

Distance from flange center $/ \mathrm{mm}$

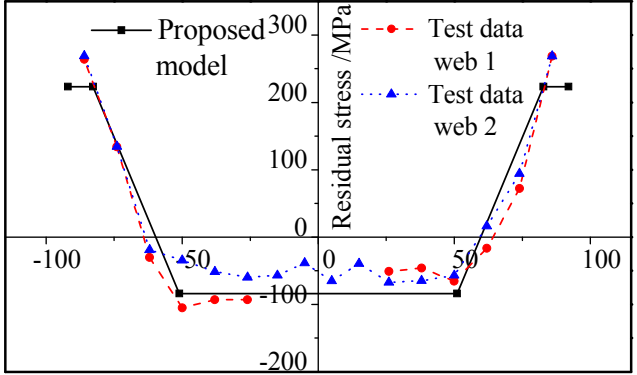

Distance from web center $/ \mathrm{mm}$

(b) After exposed to $200^{\circ} \mathrm{C}$

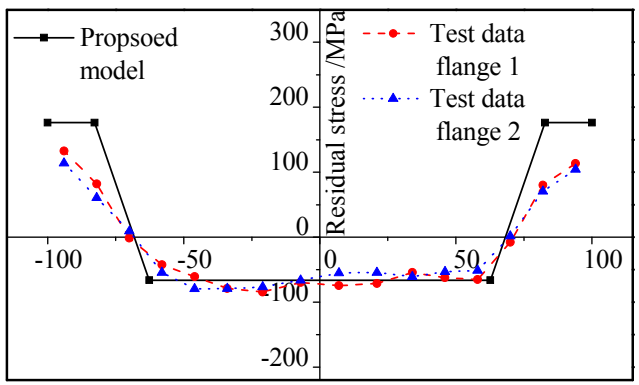

Distance from flange center $/ \mathrm{mm}$

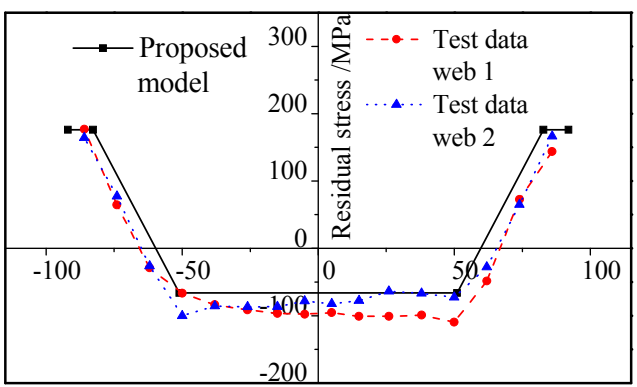

Distance from web center $/ \mathrm{mm}$

(c) After exposed to $400^{\circ} \mathrm{C}$

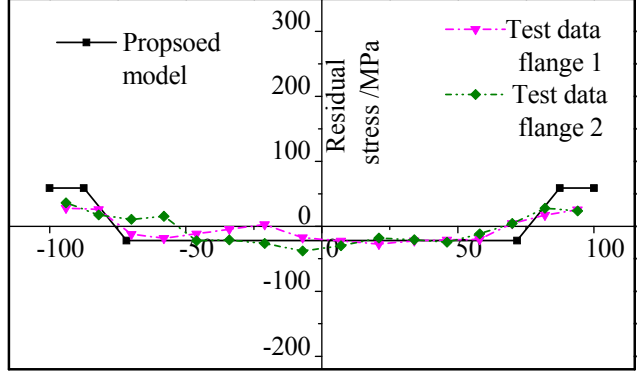

Distance from flange center $/ \mathrm{mm}$

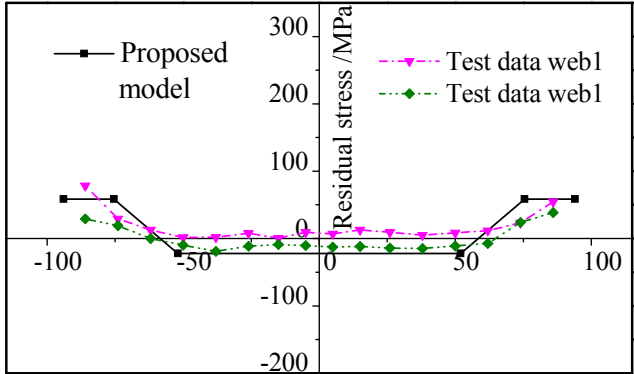

Distance from web center $/ \mathrm{mm}$

(d) After exposed to $600^{\circ} \mathrm{C}$

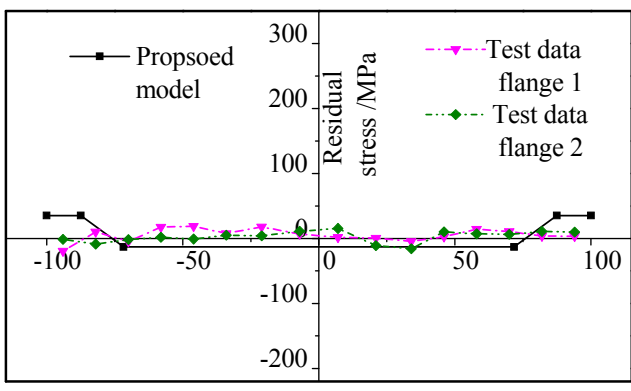

Distance from flange center $/ \mathrm{mm}$

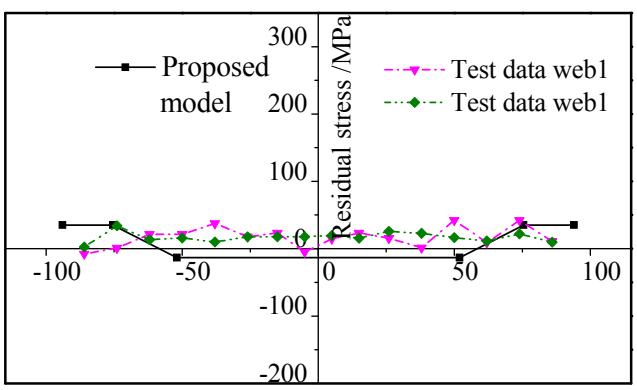

Distance from web center $/ \mathrm{mm}$

(e) After exposed to $800^{\circ} \mathrm{C}$

Figure 14. Comparison of Residual Stress from Proposed Model with Test Data for Q235 Steel Box-section Stress

Hence, it can be inferred that the proposed residual stress relation is capable of reasonably capturing residual stress distribution in welded box-section, both at room temperature and after exposure to elevated temperatures. 


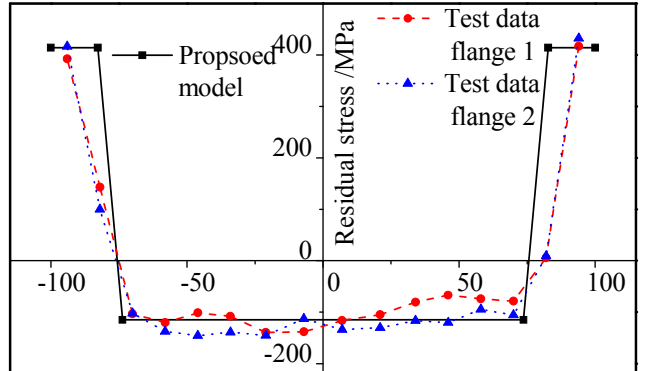

Distance from flange center $/ \mathrm{mm}$

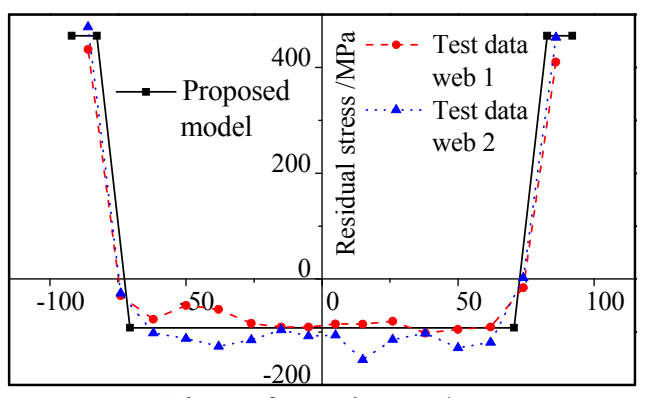

Distance from web center $/ \mathrm{mm}$

(a) At room temperature

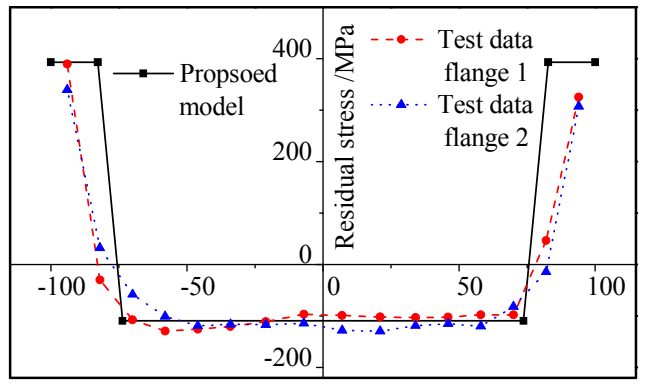

Distance from flange center $/ \mathrm{mm}$

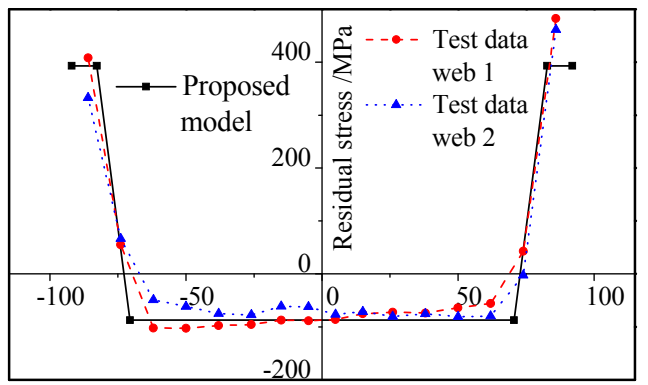

Distance from web center $/ \mathrm{mm}$

(b) After exposed to $200^{\circ} \mathrm{C}$

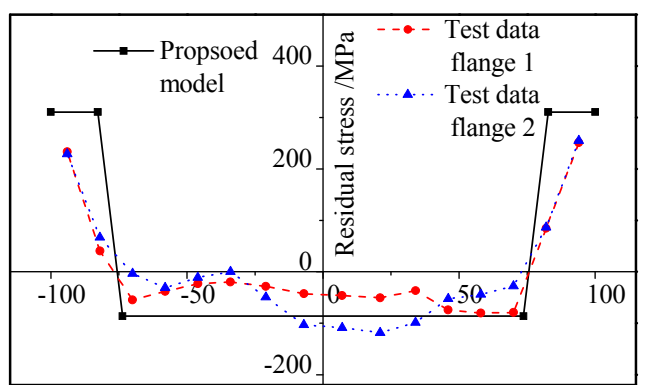

Distance from flange center $/ \mathrm{mm}$

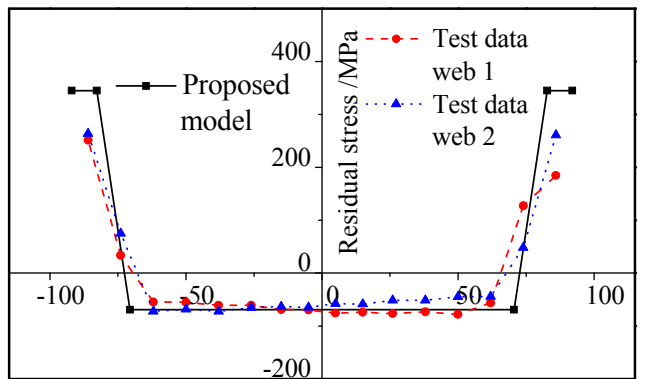

Distance from web center $/ \mathrm{mm}$

(c) After exposed to $400^{\circ} \mathrm{C}$

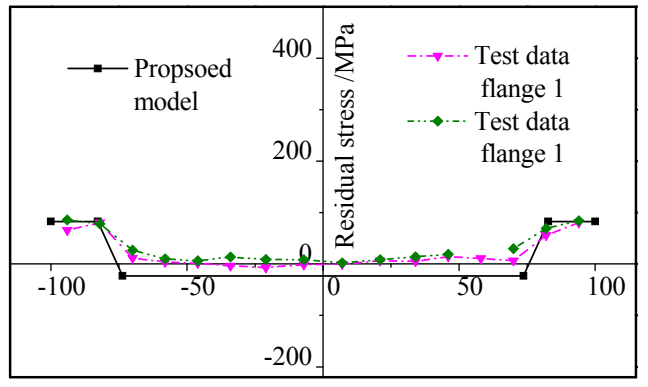

Distance from flange center $/ \mathrm{mm}$

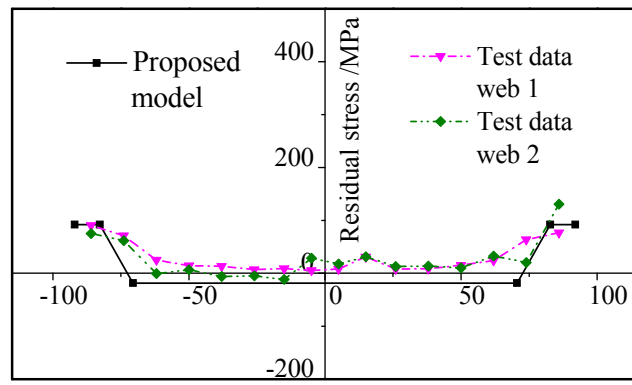

Distance from web center $/ \mathrm{mm}$

(d) After exposed to $600^{\circ} \mathrm{C}$ 


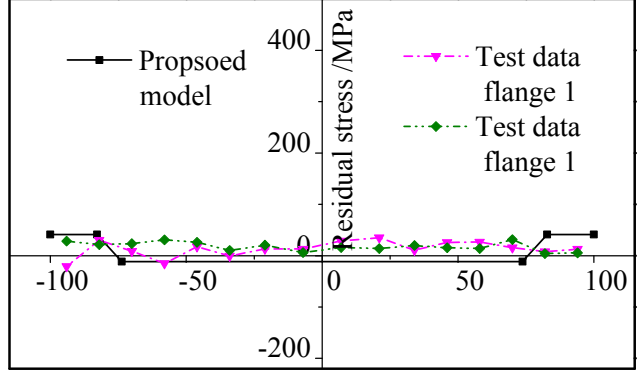

Distance from flange center $/ \mathrm{mm}$

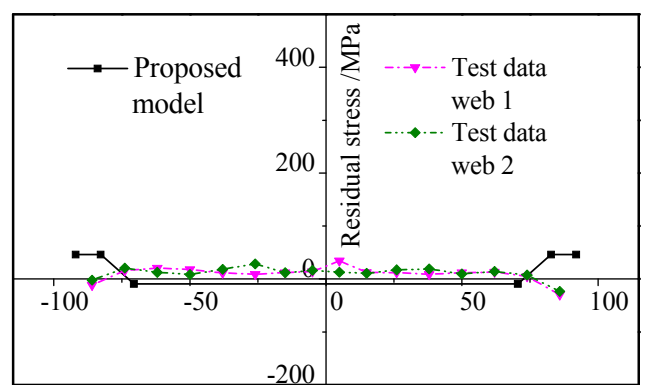

Distance from web center $/ \mathrm{mm}$

(e) After exposed to $800^{\circ} \mathrm{C}$

Figure 15. Comparison of Residual Stress from Proposed Model with Test Data for Q460 Steel Box-section

\section{CONCLUDING REMARKS}

A total of 10 box-shaped stub columns, made of mild Q235 steel and high strength Q460 steel, were tested to evaluate residual stress at ambient and after high temperature exposure. The specimens were heated to a target temperature and then allowed to cool down naturally. Through these tests the residual stress in different specimens was evaluated. Based on the results from residual stress measurements, the following conclusions can be drawn.

(1) The exposure temperature has significant influence on the magnitude of welding residual stress, and the level of residual stress decrease with an increase in peak exposure temperature.

(2) The residual stress decreases sharply once the exposure temperature exceeds $400^{\circ} \mathrm{C}$. Further, the residual stress decreases to $10 \%$ of that at ambient conditions when the exposure temperature reaches $800^{\circ} \mathrm{C}$.

(3) The temperature induced residual stress in high strength steel (Q460) sections follow the same trend as that in mild steel (Q235) section.

(4) The proposed residual stress relations compares well with test data and can be used to predict temperature induced residual stress in box-sections with plate thickness varying from $6 \mathrm{~mm}$ to $10 \mathrm{~mm}$.

\section{ACKNOWLEDGEMENT}

The authors wish to acknowledge the support from the Natural Science Foundation of China (Grant No.: 51678090), National Program on Key Research and Development Project (Grant No.: 2016YFC0701203), the Fundamental Research Funds for the Central Universities (Grant No.: 106112017CDJPT200003) and Michigan State University. Any opinions, findings, and conclusions or recommendations expressed in this paper are those of the authors and do not necessarily reflect the views of the sponsors. 


\section{REFERENCE}

[1] Tebedge, N. and Tall, L., "Residual Stress in Structural Steel Shapes - A Summary of Measured Values”, Fritz Laboratory Report, Lehigh University; 1973.

[2] Wang, W.Y., Liu, B. and Kodur, V.K.R., "Effect of Temperature on Strength and Elastic Modulus of High Strength Steel", Journal of Materials in Civil Engineering, 2013, Vol. 25, No. 2, pp. 174-182.

[3] Wang, Y.B., Li, G.Q. and Chen, S.W., "The Assessment of Residual Stresses in Welded High Strength Steel Box Sections", Journal of Constructional Steel Research, 2012, Vol. 76, pp.93-99.

[4] Ban, H.Y., Shi, G. and Shi, Y.J. et al., "Residual Stress of 460 MPa High Strength Steel Welded Box Section : Experimental Investigation and Modeling”, Thin-walled Structures 2013, Vol. 64, pp. 73-82.

[5] Li, T.J., Li, G.Q. and Wang, Y.B., "Residual Stress Tests of Welded Q690 High-strength Steel Box- and H-sections", Journal of Constructional Steel Research, 2015, Vol. 115, pp.283-289.

[6] Ma, J.L., Chan, T.M. and Young, B., "Material Properties and Residual Stresses of Cold-formed High Strength Steel Hollow Sections", Journal of Constructional Steel Research, 2015, Vol. 109, pp. 152-165.

[7] Khan, M., Paradowska, A. and Uy, B., et al., "Residual Stresses in High Strength Steel Welded Box Sections", Journal of Constructional Steel Research, 2016, Vol. 116, pp. 55-64.

[8] Wang, W.Y., Li, G.Q. and Ge, Y., "Residual Stress Study on Welded Section of High Strength Q460 Steel after Fire Exposure”, Advanced Steel Constructions, 2015, Vol. 11, No. 2, pp. 150-164.

[9] GB/T 2975-1998 Steel and Steel Products: Location and Preparation of Test Pieces for Mechanical Testing, Beijing: China Standard Press, 1998 (in Chinese).

[10] GB/T 228-2002 Metallic Materials: Tensile Testing at Ambient Temperature, Beijing: China Standard Press, 2002 (in Chinese).

[11] Wang, W.Y., Liu, T.Z. and Liu, J.P., "Experimental Study on Post-fire Mechanical Properties of High Strength Q460 Steel”. Journal of Constructional Steel Research, 2015, Vol. 114, pp. 100-109.

[12] Zhang, Y.J., Zhu, Y., Zhao, S. and Hu, K.X., "Experimental Research on Mechanical Properties of Steel Cooled in Different Modes after High Temperature Treatment", Structural Engineers, 2009, Vol. 25, No. 5, pp. 104-109 (in Chinese).

[13] Cruise, R.B. and Gardner, L., "Residual Stress Analysis of Structural Stainless Steel Sections", Journal of Constructional Steel Research, 2008, Vol. 64, pp. 352-66.

[14] Tebedge, N., Alpsten, G. and Tall, L., "Residual-stress Measurement by the Sectioning Method", Exp. Mech., 1973, Vol. 13, pp. 88-96.

[15] JGJ81-2002, Technical Specification for Welding of Steel Structure of Building, Beijing: China Architecture \& Building Press, 2002 (in Chinese).

[16] Jiang, J., Chiew, S.P., Lee, C.K. and Tiong, P.L.Y., “An Experimental Study on Residual Stresses of High Strength Steel Box Columns", Journal of Constructional Steel Research 2017, Vol. 130, pp. 12-21. 